\title{
A Case of Pigmented Fungiform Papillae of the Tongue in a Middle Eastern Woman
}

\author{
Fajer Al-Fagaan Bobby Joseph \\ Department of Diagnostic Sciences, Faculty of Dentistry, Health Sciences Centre, Kuwait University, Jabriya, Kuwait
}

\section{Key Words}

Pigmentation · Fungiform papillae · Tongue

\begin{abstract}
Objective: To report a case of pigmented fungiform papillae on the tongue. Clinical Presentation and Intervention: A 29-year-old female presented with patchy pigmented areas on her tongue of 2 years' duration. Examination of the tongue showed pigmentation confined to the fungiform papillae on the dorsum of the tongue. She was healthy and was not taking any medications and hence a diagnosis of pigmented fungiform papillae was considered. The patient was reassured of the benign nature of this condition and no treatment was given. However, a 6-month follow-up was suggested. Conclusion: Clinicians should be aware of this benign variant of lingual pigmentation to avoid confusion with pathological conditions and also to avoid unnecessary investigative procedures.

(c) 2013 S. Karger AG, Basel
\end{abstract}

\section{Introduction}

Fungiform papillae are mushroom-shaped projections scattered on the tip, lateral or dorsal parts of the tongue containing taste buds and are often unnoticed during a routine oral examination [1]. Pigmented fungiform papillae of the tongue (PFPT) were first described by Leonard [2] in 1905 as a benign condition of oral pigmentation characterized by localized hyperpigmentation confined to fungiform papillae. Among the reported cases, the vast majority occurred in African Americans, indicating that the black ethnic group is more susceptible to it than other groups [1]. Some cases have been described in Asian and Indian populations, but it is considered rare in the Middle East [3]. Although the condition is not rare and might be easily diagnosed, it is seldom mentioned in the dental or medical literature. We therefore report a case of PFPT in a patient of Middle Eastern origin.

\section{Case Report}

A 29-year-old female who presented to the Kuwait University Dental Center for orthodontic treatment was concerned about the patchy pigmented areas on her tongue of 2 years' duration. Examination of the oral mucosa showed pigmentation limited to the fungiform papillae of the dorsum of the tongue (fig. 1). The majority of the fungiform papillae were pigmented and were present in a diffuse, symmetrical pattern, predominantly on the tip and lateral aspects of the dorsum of the tongue (fig. 2). The fungiform papillae in the central area were not pigmented. The filiform papillae, which are numerous, are distributed on the anterior two thirds of the dorsum of the tongue, and the circumvallate papillae, which are the largest and less numerous, are found towards the posterior

\begin{tabular}{ll}
\hline KARGER & $\begin{array}{l}\text { C) } 2013 \text { S. Karger AG, Basel } \\
1011-7571 / 13 / 0232-0167 \$ 38.00 / 0 \quad \text { Karger }\end{array}$ \\
$\begin{array}{l}\text { E-Mail karger@karger.com } \\
\text { www.karger.com/mpp }\end{array}$ & $\begin{array}{l}\text { This is an Open Access article licensed under the terms of the } \\
\text { Creative Commons Attribution-NonCommercial 3.0 Un- } \\
\text { ported license (CC BY-NC) (www.karger.com/OA-license), } \\
\text { applicable to the online version of the article only. Distribu- } \\
\text { tion permitted for non-commercial purposes only. }\end{array}$
\end{tabular}

Dr. Bobby Joseph

Department of Diagnostic Sciences

Faculty of Dentistry, Health Sciences Centre, Kuwait University

Kuwait City 13110 (Kuwait)

E-Mail bobby@hsc.edu.kw 
Fig. 1. Pigmented fungiform papillae on the lateral border and tip of the tongue.

Fig. 2. Pigmented fungiform papillae involving the dorsum of the tongue.
1

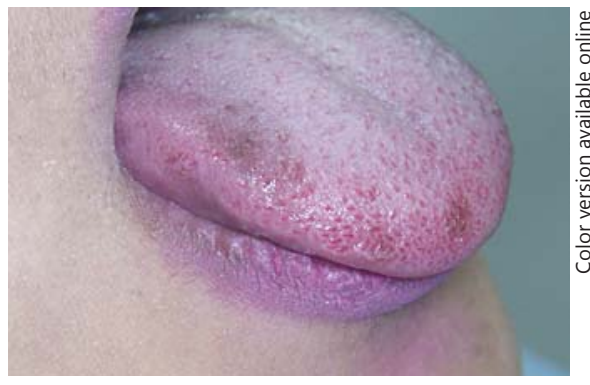

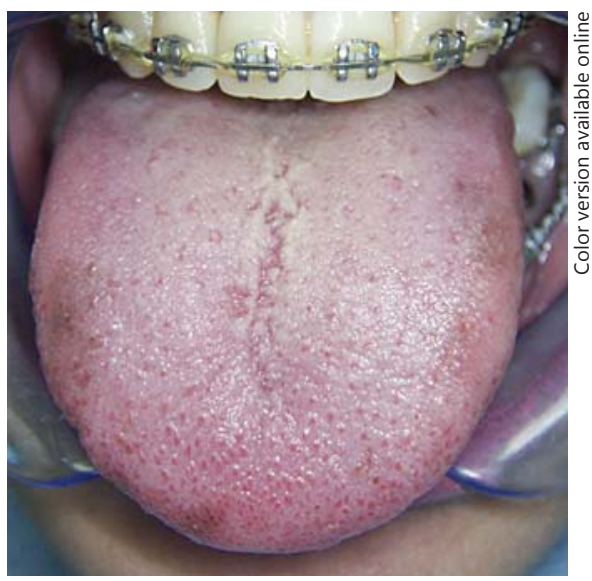

side of the tongue. Fungiform papillae are discrete pink projections concentrated along the anterior and lateral aspects of the tongue. She had no accompanying symptoms. She was healthy and was not taking any medications. The parents did not present similar pigmentation of the oral mucosa. A diagnosis of pigmented fungiform papillae was considered. The patient was reassured of the benign nature of the condition and a 6-month follow-up was recommended.

\section{Discussion}

This was a case of PFPT with diffuse pigmentation predominantly at the tip and the lateral aspects of the tongue. The fungiform papillae in the central area were not pigmented. The surface of the tongue is covered by three types of papillae: filiform, fungiform and circumvallate [4]. The clinical features of PFPT include well-circumscribed hyperpigmentation confined to the fungiform papillae and lesions are generally asymptomatic. The disorder usually starts during late infancy and is not progressive. Clinically this condition occurs in the second and third decades with a predilection for females [1]. There are no alterations in the nail or other cutaneous structures [1]. The present case had similar features.

Holzwanger et al. [1] have classified PFPT into three clinical types. The first type is a well-circumscribed hyperpigmented area involving all the fungiform papillae on the anterolateral side or towards the tip of the tongue. The second type shows hyperpigmentation involving 3-7 fungiform papillae scattered on the dorsal surface of the tongue, and in the third type hyperpigmentation is seen on every fungiform papilla on the dorsum of the tongue. In our patient, the pattern of distribution was of the first type.
PFPT is generally considered as a common finding in African American patients [4]. In 1973, Holzwanger et al. [1] examined 300 random individuals and came to the conclusion that among blacks, $30 \%$ of men and $25 \%$ of women exhibited some hyperpigmentation of fungiform papillae, whereas among Asians and Caucasians the prevalence is very low $[3,5]$. The histopathological features of PFPT show numerous macrophages in the lamina propria which stain positive for melanin with Fontana-Masson and negative for iron with Prussian blue with no evidence of an inflammatory infiltrate [6].

The pathogenesis of pigmented fungiform papillae is still unclear. Oh et al. [7] have reported associations with dermatological disorders such as linear circumflex ichthyosis and lichen planus, and an association with systemic diseases such as hemochromatosis, scleroderma, pernicious anemia, and iron deficiency anemia has also been described, although most patients are healthy [7]. Besides ethnicity, Werchniak et al. [6] reported pigmented fungiform papilla in a mother and her daughter, which lends support to the idea that a genetic predisposition may be a contributing factor. There is no effective treatment reported as in this case where the patient was reassured of the benign nature of her condition. However, in one case associated with iron deficiency anemia, a moderate reduction in pigmentation was reported after treatment of the anemia [6].

Differential diagnosis include other causes of pigmentation of the oral mucosa such as hemochromatosis, pernicious anemia, amalgam tattoo, Peutz-Jeghers syndrome, Addison's disease, von Recklinghausen syndrome and melanocytic nevus [8]. Urbina and Sudy [9] have observed discrete pigmentation of the papilla of the tongue in patients with Laugier-Hunziker syndrome and consid- 
er the underlying mechanism of pigmentation to be the same. However, according to Marcoval et al. [10], Laugier-Hunziker is a rare condition associated with longitudinal melanonychia and not related to PFPT. The differential diagnosis could include Peutz-Jeghers syndrome which is characterized by discrete, brown to blue-black macules around the mouth, nose and eyes and associated with hamartomatous gastrointestinal polyposis, which carries a high risk for malignancy [1].

\section{Conclusion}

Clinicians should be aware of this benign condition of lingual pigmentation to avoid incorrect diagnosis and unnecessary investigative procedures.

\section{References}

$>1$ Holzwanger JM, Rudolph RI, Heaton CL: Pigmented fungiform papillae of the tongue: a common variant of oral pigmentation. Int J Dermatol 1974;13:403-408.

-2 Leonard TMR: Ankylostomiasis or uncinariasis. JAMA 1905;45:588-594.

$\checkmark 3$ Scarf CE, Marks R: Pigmented fungiform papillae of the tongue in an Asian man. Australas J Dermatol 2003;44:149-151.

4 Boshell JL, Wilborn WH, Singh BB: A correlative light microscopic, transmission and scanning electron microscopic study of the dorsum of human tongue. Scan Electron Microsc 1980;3:505-510.
5 Tan C, Liu Y, Min Z-S, et al: A clinical analysis of 58 Chinese cases of pigmented fungiform papillae of the tongue. J Eur Acad Dermatol Venereol 2012, E-pub ahead of print.

6 Werchniak AE, Storm CA, Dinulos JG: Hyperpigmented patches on the tongue of a young girl. Pigmented fungiform papillae of the tongue. Arch Dermatol 2004; 140:12751280.

7 Oh CK, Kim MB, Jang HS, et al: A case of pigmented fungiform papillae of the tongue in an Asian male. J Dermatol 2000;27:350-351.
8 Jang YH, Lee JY, Kang HY, et al: Oestrogen and progesterone receptor expression in melasma: an immunohistochemical analysis. J Eur Acd Dermatol Venereol 2010;24:13121316.

9 Urbina F, Sudy E: Pigmented fungiform papillae of the tongue in Laugier disease or Laugier-Hunziker syndrome. Actas Dermosifiliogr 2013;104:173-174.

10 Marcoval J, Notario J, Martín-Sala S, et al: Pigmentation of the fungiform papillae of the tongue: a report of 2 cases. Actas Dermosifiliogr 2011;102:739-740. 